\title{
Midwives' Time and Presence: A Key Factor in Facilitating Breastfeeding Support for New Mothers
}

\author{
Danielle Gleeson, Karen Flowers, and Jennifer Fenwick
}

BACKGROUND: There is now a plethora of work that has examined new mothers' experiences of receiving breastfeeding support. However, there remains limited literature describing women's experiences of receiving this support from midwives in the early postnatal period.

AIM: The study aimed to explore and describe women's experiences of receiving breastfeeding support from midwives in the early postnatal period.

METHOD: A qualitative descriptive approach was used. Six first-time mothers who initiated breastfeeding after birth consented to be involved and participated in an in-depth interview. The techniques associated with dimensional analysis and constant comparison were used to analyze the data set.

FINDINGS: Two categories were identified that described women's experiences of midwifery breastfeeding support. These were related to the midwives' ability to spend and give the gift of time to women. Alternatively, the midwife's busyness and inability to be present for the woman was considered a barrier to receiving positive breastfeeding support and the woman's ability to problem solve any breastfeeding issues.

CONCLUSION: The findings of this study confirm both the importance of midwives spending time providing breastfeeding support and the negative consequences of a lack of time given for the provision of this support. Mothers have asked for midwives to be present; investing time in them, listening to them, and helping them solve problems. Current care models present barriers contributing to both the perceptions and realities of midwives' lack of time, presenting a need to reconsider the design of maternity care environments and to adopt a caseload approach where women receive relationship-based care.

KEYWORDS: breastfeeding; support; presence; midwifery; time

\section{INTRODUCTION}

Breastfeeding is recognized as the optimal form of infant feeding, offering numerous health benefits to both the infant and mother (House of Representatives, 2007; World Health Organization [WHO], 2007). Much research has been conducted to study the physical, psychological, and economic benefits of breastfeeding; with each showing that breastfeeding is superior to any other method of infant feeding and provides benefits in each of the areas studied (Horta \& Victora, 2013; Ladomenou,
Moschandreas, Kafatos, Tselentis, \& Galanakis, 2010; WHO, 2009).

In line with the WHO (2002) recommendations, the National Health and Medical Research Council (NHMRC; 2003) of Australia recommended exclusive breastfeeding for at least 6 months for maximum nutritional and health benefits. At this time, the NHMRC set the target of $80 \%$ of mothers to be fully breastfeeding their infant at 6 months within 10 years. The latest available Australian statistics demonstrate that although there are high breastfeeding initiation rates (96\%), 
a large proportion of women cease breastfeeding within the first 3 months of birth with only 15\% feeding at 6 months (Australian Institute of Health and Welfare, 2012).

Although women give numerous reasons for stopping breastfeeding, research shows that supportive health practices such as practical help and encouraging breastfeeding attitudes can make a positive difference (Hauck, Fenwick, Daliwal, Butt, \& Schmied, 2011). The properties of positive support identified by Sheehan, Schmied, and Barclay (2009) were "emotional support," "being available," and "staying with you." These authors used mothers' descriptions of positive support behaviors and inverted negative support behaviors to provide a list of positive breastfeeding support. Positive support consisted of "emotional support, acknowledgement, approval, being available, providing practical support, staying with you, being sensitive and being flexible" (Sheehan et al., 2009, p. 146). On the whole, these interventions were perceived by mothers to be positive, helpful, and/or supportive to breastfeeding and were consistently associated with an increased duration and exclusivity of breastfeeding, aligning with the findings of other studies that described positive breastfeeding support (Britton, McCormick, Renfrew, Wade, \& King, 2007; Hannula, Kaunonen, \& Tarkka, 2008; Henderson \& Redshaw, 2011). Likewise, in a review of professional support for breastfeeding, the interventions constituting breastfeeding support were observation, guidance, communication, encouragement, information, and technical assistance (Hannula et al., 2008).

Conversely, new mothers have also described how health professionals' practices can be unhelpful in assisting them establish lactation (Backstrom, Wahn, \& Ekstrom, 2010). Conflicting and incorrect advice are commonly described by women in the literature (Sarasua, Clausen, \& Frunchak, 2009) and may be attributable to the significant variations in midwives' knowledge of current breastfeeding evidence (Cantrill, Creedy, \& Cooke, 2003). The unsolicited provision of formula and pacifiers (Hegney, Fallon, \& O’Brien, 2008; Sarasua et al., 2009) and rough handling (Sheehan et al., 2009) add to this list.

In Australia, midwives are the maternity health care professional most likely to provide care to new mothers in the early postpartum period (Department of Health and Ageing, 2009). Therefore, midwives are in an opportune position to provide early breastfeeding support. However, there remains limited literature describing women's experiences of receiving support from midwives in the early postnatal period. Furthermore, many related studies have been conducted in the United
States (see e.g., Phillips, 2011; Raisler, 2000; Tender et al., 2009) where models of maternity care differ markedly from those in Australia.

The study described in this article thus aimed to describe first time mothers' experiences of midwifery support in the early postnatal period. The study sought to generate knowledge and understanding that could assist midwives to better understand the experiences of new mothers when receiving breastfeeding support and to develop support strategies toward a more positive breastfeeding experience.

\section{AIM}

The qualitative descriptive study outlined in this article aimed to describe women's experiences of receiving midwifery breastfeeding support during the first 3 days following birth.

\section{METHODS}

Qualitative approaches seek to discover the experience of the situation from the participants' perspective and to answer questions that focus on social experience, how this experience is created, and how it gives meaning to human life (Denzin \& Lincoln, 2011). A qualitative descriptive approach combines sampling, collection, and analysis of data and techniques for representation of data while allowing the researcher to remain close to the data (Sandelowski, 2000). The qualitative descriptive method aims to produce a rich description of the phenomena within the social world context (Denzin \& Lincoln, 2011).

\section{Participants and Recruitment}

Women were eligible to participate in the study if they were a first time mother with a full-term healthy baby who had commenced breastfeeding after birth. Women who could not speak English or were less than 18 years old were excluded. The number of women participating in the study was based on reaching data saturation. Data saturation is the point at which the information gathered from the participants becomes repetitive and analysis reveals no new concepts (Munhall, 2011).

To recruit new mothers for this study, midwives on the postnatal wards at a metropolitan tertiary hospital were provided with information regarding the study 
including the aims and inclusion criteria. Midwives contacted the researcher when a potential participant was identified. After confirming suitability, the researcher approached the new mother, introduced herself as a researcher with an interest in breastfeeding, provided an information letter and consent form, and returned later that day to answer questions and gain written consent if the mother wished to participate.

The final sample consisted of six women, three receiving public sector care and three within the private sector. Four of the six women were White, with three Australian born and one born in the United Kingdom. The other two women were Asian (Japanese) and Pacific Islander (Samoan) in origin. The woman ranged from 20 to 44 years of age, with two women younger than 25 years, two between 26 and 31 years, one between 32 and 38 years, and one aged 44 years. One of the women had primary school as her highest level of education, three had secondary school, and two had attained tertiary level qualifications.

\section{Data Collection}

Women participated in a semistructured interview within 4 weeks of giving birth. Conducting the interviews within this time frame allowed participants to effectively recall their experiences and decreased the effect of other health professionals' influences on participants' experiences of breastfeeding support (Waldenstrom, 2004).

The 1-2 $\mathrm{hr}$ interviews were conducted with each new mother in their home. Questions were broad and based on the current literature around breastfeeding support. For example: Tell me about your experience of receiving breastfeeding support from midwives at the hospital? What were your expectations of the breastfeeding support that you would receive from midwives?

Each interview was recorded, transcribed, and analyzed prior to the following interview being undertaken. The analysis guided the reshaping of questions for the next interview.

\section{Data Analysis}

The techniques associated with dimensional analysis and constant comparison were used to assist the researcher to analyze the data set and describe the phenomenon. Constant comparative analysis, often referred to as the corner stone of grounded theory, stimulates the researcher's thoughts, leading them to both describe and explain what is happening (Denzin \& Lincoln, 2011). Dimensional analysis, as originally defined and described by Schatzman (1991) reflects the normal cognitive processes of a person as they try to understand and describe a phenomenon. This can be reflected in how a person tells a story in that the objects and events within the story are designated as the context or a condition to the actions or interactions that are central to the story or situation. Alternatively, they may be presented as a consequence of these actions or interactions (Schatzman, 1991).

In the initial stage of dimensional analysis, the objects or aspects of the story are discovered and become dimensions and their properties. The first step in the process was open coding as described by Glaser (1978). Open or line by line coding involved breaking down the data into as many codes as possible. Questions were asked of the data such as, "What is happening in this data?" and "What is the participant actually saying here?" These questions kept the researchers theoretically sensitive, that is, able to make sense of the data by making connections, identifying patterns, and establishing relationships between each data segment (Glaser, 1978). As more interview data were collected, the codes were clustered to develop the categories and their properties. Open coding identified 113 initial categories.

The second stage of the analysis involved the "integration of categories and their properties" (Glaser, 1978 , p. 108). This integration was enabled by the comparison of incidents to properties of categories to determine how they related to each other. Through this process, categories and their properties began to have more meaning and a story started to develop. NVivo 7 software was used to help manage the data set (QSR International, 2006).

\section{Ethical Considerations}

Ethical approval for this study was sought and given from the Australian Catholic University Human Research Ethics Committee. Additional approval was sought and given from the Mater Health Service's Human Research Ethics Committee as the women who participated in the study were recruited from this health service.

The study was conducted in accordance with the NHMRC (2007) recommendations for ethical conduct in human research in all areas including consent, confidentiality, and data storage. Particular consideration 
was given to the vulnerability of new mothers and the potential emotional risk involved in discussing their breastfeeding experiences. These considerations were reflected in the inclusion criteria and research design. The research did not contain interventions, treatments or therapeutic techniques, and participants were not from any particularly vulnerable groups. The research was categorized as minimal or low risk, as defined by the NHMRC (2007).

\section{FINDINGS}

The findings presented in this article focus on the concept of time which women articulated as important to their experiences and perceptions of breastfeeding support offered by midwives. Midwives who spent time with women were highly valued. Conversely, midwives' busyness and inability to be present for women was considered a barrier to receiving positive breastfeeding support.

\section{Spending Time With Women}

The midwives' ability to invest and prioritize their time so that women perceived they were afforded personalized breastfeeding support was crucial to women and the process of being able to work out how to breastfeed. Behaviors such as watching, listening, explaining, answering questions, demonstrating, encouraging, sitting down, and giving one on one attention were how women described midwives who spent time with them and in so doing made them the focus of care. This was summarized well by Susan when she said, "I guess the ideal midwife would sit with you, explain about caring for your baby ... Watch you breastfeed, spend some time ... The ideal person would be there to listen, to explain."

Women spoke very positively of the midwives who spent time with them as they perceived that it made a difference to their experiences and helped them to figure out what they needed to do. The following comment from Anne is an example:

I think the most beneficial thing is if they spend time with you ... the midwives that just seemed to spend more time with me and come to me when I buzzed and then watch me put her on and stay with me for a little while, you know, they seemed to make the difference.
Rhonda discussed spending time in terms of the midwives being physically available and in the room.

When they are just there while you try to feed, yeah, just being present, just in case you need them ... that was the best thing they could do really.

The ability of midwives to create a sense of time and space where they could provide focused attention on the woman and her breastfeeding experience emerged as one of the key factors that women felt best assisted them learn how to breastfeed during the very early postnatal period. During the data analysis process, it became evident that questions pertaining to whether it was the length of time as opposed to what the midwife did during the time needed to be posed. On further questioning of the women, it was identified that the time spent with women varied greatly from 10 to $30 \mathrm{~min}$ or more. Women verbalized that it was the emotional support, assistance, and advice provided that made their view of time spent so positive. Consequently in these circumstances, women felt midwives helped them problem solve by facilitating opportunities to discuss all their thoughts and feelings related to these early breastfeeding experiences.

I was having a meltdown and a midwife just came and sat with me for a bit ... just listened and helped me with the problems we were having, which was really good ... it was nice having someone to sit in there with us making sure, double checking he was attached properly and offering suggestions on how to make each of us a bit happier. That made it all so much easier. (Jessica)

In contrast, when the midwives appeared unavailable to women and time was at a premium, women struggled in their effort to successfully problem solve their way through the early up's and downs of being a new breastfeeding mother.

\section{Time Poor: Midwives' Busyness}

This theme groups together a range of actions and interactions that women described as hindering both the provision and reception of midwifery breastfeeding 
support. For the most part, these were a reflection of the woman's perceptions that the postnatal ward was a busy and somewhat chaotic environment. The buzzer (call bell) featured heavily in many women's conversations. Several of the women commented that the midwife would arrive to answer the buzzer long after the need for assistance had arisen:

On a number of occasions, it was $45 \mathrm{~min}$ to an hour before anyone would even pop their head in ... so by that time the feed was nearly over... (Ann)

Delayed response to their call bell and the fact that they could hear other buzzers going heightened the women's sense that everyone was very busy and in so doing often generated feeling of guilt for seeking assistance. The following extract from Soko's interview demonstrates what was a common dilemma for women.

I just thought if I ring the bell, maybe they might be too busy. I can partly hear the babies crying and the beeping sounds to calling the midwife and I thought ooh they might be a bit busy and I was a bit hesitate [sic] to do that...

As a result of the midwives' busyness, women perceived that their problems were often normalized or dismissed. For example, Lily stated, "My nipple was very sore. They (midwives) said it's supposed to be like that ... might take a couple of weeks ..." Ann tried to seek information on expressing after she had trouble breastfeeding but felt that the midwife dismissed her attempts to solve a problem:

The expressing ... that was just sort of, you know, when I mentioned that, it was just disregarded. She just said there's no point in doing that ... Some of them were just a bit dismissive and didn't fully appreciate where I was coming from...

Within this context, women also reported receiving conflicting advice and having midwives discount other advice which was similarly reported as unsupportive. Conflicting advice was common and caused women distress and frustration. Susan's comment is reminiscent of others: "She said that's normal . . . so I just thought that's normal and didn't mention anything. So the next morning I just happened to mention it and they said 'oh no, that's not good"' The following extracts from Ann and Rhonda's interview data differentiated conflicting advice from offering alternatives; the latter of which they believed was supportive of breastfeeding.

Maybe if just more alternatives were offered to me in the hospital, it might have made a difference. (Ann)

as opposed,

So just sort of trying out different things that they've told me ... that sort of helped ... It was good to hear all the options. (Rhonda)

\section{DISCUSSION}

A key finding of this study was that women who perceived midwives had time for them had a more positive breastfeeding experience than those mothers who perceived midwives to be busy and unavailable (Gleeson, 2012). The midwives' capacity to spend time with women was perceived as critical to her success at problem solving her way through the early days of learning to mother and breastfeed her baby. For the women in this study, midwives spending time was synonymous with midwives providing positive breastfeeding support. As previously reported in a grounded theory study of mothers' expectations and experiences of infant feeding support, Sheehan et al. (2009) identified three properties of positive support. Two of these were being available and staying with you, both of which align closely with the concept of the midwife creating the time in which she can be present with the woman. In Sheehan et al's (2009) work, women similarly focused on the value of the midwives being present rather than what they actually did during that time.

Presence is a term well-defined in nursing and midwifery literature (Kennedy, Anderson, \& Leap, 2010). Pembroke and Pembroke (2008) used an integration of philosophical reports and women's personal reflections to offer insight into the concept of presence in midwifery. They found that one of the two focal concepts of midwifery presence was availability, adding "to be available to the woman involves listening to her and follow- 
ing her lead" (p. 325). Being available and listening were also identified as important aspects of support to the mothers in this study. A recent meta-synthesis, not published when this study was undertaken, of women's perceptions and experiences of breastfeeding support found that breastfeeding support occurs along a continuum from "authentic presence" to "disconnected encounters" (Schmied, Beake, Sheehan, McCourt, \& Dykes, 2011, p. 51). Authentic presence described the emotional and practical care given by peers or professionals that mothers found supportive and was made up of seven themes: "being there for me," "empathetic approach," "taking time/touching base," "providing affirmation," "being responsive," "sharing the experience," and "having a relationship" (p. 54). The theme of "midwives spending time" supports Schmied et al.s (2011) findings with each of the actions and interactions featuring in the descriptions of authentic presence and facilitative style, occurring at the "supportive" end of the continuum.

The direct opposite of providing women with a sense of time and presence were situations where women experienced midwives "popping" in and out often after waiting considerable lengths of time for the midwife to appear. Like others have reported (see e.g., Schmied et al., 2011), women in this study commonly blamed the work environment rather than on the midwives themselves. Women stated that midwives "looked busy" and commonly stated that they were indeed busy and understaffed. A synthesis of 47 qualitative papers, on breastfeeding support, found that midwives consistently raised concerns about time pressures on the postnatal ward (McInnes \& Chambers, 2008). As a result, women reported feeling guilty and reluctant to ask for help. Schmied et al. (2011) similarly found that mothers who could hear bells going and perceived staff to be "too busy" to answer call buttons, tended to "struggle on quietly" by themselves (p. 57).

The concept of busyness on the postnatal ward and midwives' justification for this has been explored in several Australian studies. Cooke, Cantrill, and Creedy (2009) accessed data from a national survey of Australian midwives related to their practice supporting the first breastfeed. The midwives identified limitations to breastfeeding support imposed by their workloads and the apparent higher priorities of other clinical matters. Gilmour, Hall, McIntyre, Gillies, and Harrison's (2009) descriptive study of factors associated with early breastfeeding cessation reiterated this. Australian midwives in this study revealed that they were sometimes too busy to provide breastfeeding assistance for mothers in hospital. Again, they blamed workloads and competing priorities such as the needs of mothers post-caesarean as impacting on their ability to provide breastfeeding support. Another Australian study (Rayner, Forster, McLachlan, Yelland, \& Davey, 2008) sought the views and experiences of midwives providing postnatal care in Victorian hospitals through questionnaires and interviews. They found that midwives were dissatisfied with their ability to provide postnatal care, including breastfeeding support. The midwives identified organizational barriers such as a reduced length of postnatal stay, staffing issues, and the busy and chaotic nature of the wards as time limiting and, thus, barriers to the provision of support.

\section{IMPLICATIONS}

The design and administration of postnatal units continues to undervalue the importance of early breastfeeding support for new mothers. There is a need to place greater emphasis on women's need for this support and to reconsider the adequacy of staffing in hospital postnatal units. Postnatal care has commonly been described as the Cinderella of maternity service. Resources are often diverted away from this area of care in favor of birthing services. Some maternity services are introducing measures in an effort to redistribute midwives' time to allow for more direct care of women. For example, the "Releasing time to care" program being implemented by the United Kingdom's National Health Service (NHS) is currently redesigning the way in which nurses and midwives work on inpatient wards, resulting in a $20 \%$ increase in the time allowed for direct care (Wilson, 2009). A revised version of this program is currently being implemented within Queensland Health and has likewise witnessed a significant improvement in the time available for direct care to women (Caddick, personal communication, October 5, 2011).

Design features such as call systems must also be more effective. After the interviews for this study were conducted, the hospital where the women were recruited underwent a major redevelopment. A new call system was implemented that sent pages to each woman's allocated midwife. Midwives set their pagers to vibrate to ensure women were not disturbed by pager alerts. The call system was programmed to escalate an unanswered call by sending an alert to an allocated buddy midwife. Anecdotal evidence suggests that because the new system buzzers are answered in a more timely fashion, the perception of busyness seemed to decrease for both midwives and mothers. 
However, these are cosmetic changes only and arguably do not address the real cause of the problem. Providing postnatal care in an "acute" nursing care model is ineffective and consistently rated poorly by women (Sandall, Page, Homer, \& Leap, 2008). The evidence is now clear; women accessing continuity of midwifery care across pregnancy, birth, and early parenting have better maternal and neonatal outcomes (Sandall, Soltani, Gates, Shennan, \& Devane, 2013). Longitudinal relational-based care enhances the midwife's ability to be truly "present" with a woman in all aspects of her care. The very nature of how care is organized in these models sees the redistribution of midwifery time; facilitating midwifery presence and relational-based care (Fereday, Collins, Turnbull, Pincombe, \& Oster, 2009; Sandall et al., 2008; Williams, Lago, Lainchbury, \& Eagar, 2010). Although not all studies testing the effectiveness of caseload care measure breastfeeding outcomes, those that do show positive results with duration of breastfeeding increase (Backstrom et al., 2010).

\section{LIMITATIONS}

The limitations of this study relate to sampling and the constraints applied to complete this study as part of a master's degree. The sampling criteria, applied for ethical reasons, meant that young women and those who were non-English-speaking were not represented in the data. This may have led to some differences in the findings. The experience of indigenous mothers was also not represented. In addition, the study was carried out in a single large tertiary facility. Although these limitations need to be considered when interpreting the findings, the study nonetheless provides valuable insight into this group of women's experiences of positive midwifery breastfeeding support.

\section{CONCLUSION}

The findings of this study confirm the importance of midwives spending time providing breastfeeding support to women having their first baby. For women, the midwives' ability to demonstrate "presence" during the time spent with her was essential in helping her successfully negotiate, problem solve, and feel positive about her early breastfeeding experiences. Creating spaces round new mothers where midwives can spend time engaging deeply with women is important. Postnatal care needs to be adequately resourced. In the longer term, maternity care needs to be restructured so that women have access to models that promote longitudinal relational-based care, such as caseload. In these models, postnatal care is equally valued and an important part of the midwives full scope of practice.

\section{REFERENCES}

Australian Institute of Health and Welfare. (2012). Australia's Health 2012. Retrieved from http://www.aihw.gov.au/ WorkArea/DownloadAsset.aspx?id=10737422169

Backstrom, C., Wahn, E., \& Ekstrom, A. (2010). Two sides of breastfeeding support: Experiences of women and midwives. International Breastfeeding Journal, 5(1), 20.

Britton, C., McCormick, F. M., Renfrew, M. J., Wade, A., \& King, S. E. (2007). Support for breastfeeding mothers. Cochrane Database of Systematic Reviews, (1), CD001141. http://dx.doi.org/10.1002/14651858 .CD001141.pub3

Cantrill, R., Creedy, D., \& Cooke, M. (2003). How midwives learn about breastfeeding. Australian Midwifery, 16(2), 11-16.

Cooke, M., Cantrill, R. M., \& Creedy, D. K. (2009). Midwives' reported practice supporting the first breastfeed. Maternal \& Child Nutrition, 5(4), 334-346. http://dx.doi. org/10.1111/j.1740-8709.2008.00173.x

Denzin, N., \& Lincoln, Y. (2011). SAGE handbook of qualitative research (4th ed.). Thousand Oaks, CA: Sage.

Department of Health and Ageing. (2009). Improving maternity services in Australia: Report of the Maternity Services Review. Canberra, Australia: Commonwealth of Australia.

Fereday, J., Collins, C., Turnbull, D., Pincombe, J., \& Oster, C. (2009). An evaluation of Midwifery Group Practice. Part II: Women's satisfaction. Women and Birth, 22(1), 11-16. http://dx.doi.org/10.1016/j.wombi.2008.08.001

Gilmour, C., Hall, H., McIntyre, M., Gillies, L., \& Harrison, B. (2009). Factors associated with early breastfeeding cessation in Frankston, Victoria: A descriptive study. Breastfeeding Review, 17(2), 13-19.

Glaser, B. (1978). Theoretical sensitivity: Advances in the methodology of grounded theory. Mill Valley, CA: Sociology Press.

Gleeson, D. (2012). Working it out: New mother's experiences of learning to breastfeed (Unpublished master's thesis). Australian Catholic University, Brisbane, Australia.

Hannula, L., Kaunonen, M., \& Tarkka, M. T. (2008). A systematic review of professional support interventions for breastfeeding. Journal of Clinical Nursing, 17(9), 1132-1143. 
Hauck, Y., Fenwick, J., Daliwal, S., Butt, J., \& Schmied, V. (2011). The association between women's perceptions of professional support and problems experienced on breastfeeding cessation: A Western Australian study. Journal of Human Lactation, 27(1), 49-57. http://dx.doi.org/10.1177/0890334410386956

Hegney, D., Fallon, T., \& O’Brien, M. L. (2008). Against all odds: A retrospective case-controlled study of women who experienced extraordinary breastfeeding problems. Journal of Clinical Nursing, 17(9), 1182-1192.

Henderson, J., \& Redshaw, M. (2011). Midwifery factors associated with successful breastfeeding. Child: Care, Health and Development, 37(5), 744-753. http://dx.doi. org/10.1111/j.1365-2214.2010.01177.x

Horta, B., \& Victora, C. (2013) Long-term effects of breastfeeding: A systematic review. Retrieved from http://apps.who .int/iris/bitstream/10665/79198/1/9789241505307 _eng.pdf

House of Representatives. (2007). The best start: Report on the enquiry into the health benefits of breastfeeding. Canberra, Australia: Australian Government Publishing Service.

Kennedy, H., Anderson, T., \& Leap, N. (2010). Midwifery presence: Philosophy, science and art. In D. Walsh \& S. Downe (Eds.), Essential midwifery practice: Intrapartum care (pp. 105-123). Oxford, United Kingdom: Wiley.

Ladomenou, F., Moschandreas, J., Kafatos, A., Tselentis, Y., \& Galanakis, E. (2010). Protective effect of exclusive breastfeeding against infections during infancy: A prospective study. Archives of Disease in Childhood, 95, 1004-1008. http://dx.doi/10.1136/adc.2009.169912

McInnes, R., \& Chambers, J. (2008). Supporting breastfeeding mothers: Qualitative synthesis. Journal of Advanced Nursing, 62(4), 407-427.

Munhall, P. (2011). Nursing research: A qualitative perspective. London, United Kingdom: Jones and Bartlett.

National Health and Medical Research Council. (2003). Dietary guidelines for children and adults in Australia incorporating the infant feeding guidelines for health workers. Canberra, Australia: Australian Government Publishing Service.

National Health and Medical Research Council. (2007). National statement on ethical conduct in human research. Canberra, Australia: Australian Government Publishing Service.

Pembroke, N., \& Pembroke, J. (2008). The spirituality of presence in midwifery care. Midwifery, 24(3), 321-327. http://dx.doi.org/10.1016/j.midw.2006.10.004

Phillips, K. (2011). First-time breastfeeding mothers: Perceptions and lived experiences with breastfeeding. International Journal of Childbirth Education, 26(3), 17-20.
QSR International. (2006). NVivo (Version 7) [qualitative data analysis software]. Retrieved from http://www .qsrinternational.com/products_nvivo.aspx

Raisler, J. (2000). Against the odds: Breastfeeding experiences of low income mothers. Journal of Midwifery \& Women's Health, 45(3), 253-263.

Rayner, J., Forster, D., McLachlan, H., Yelland, J., \& Davey, M. (2008). A state-wide review of hospital postnatal care in Victoria, Australia: The views and experiences of midwives. Midwifery, 24(3), 310-320. http://dx.doi. org/10.1016/j.midw.2006.10.008

Sandall, J., Page, L., Homer, C., \& Leap, N. (2008). Continuity of care-what is the evidence? In C. Homer, P. Brody \& N. Leap (Eds.), Midwifery continuity of care: A practical guide. Sydney, Australia: Churchill Livingstone.

Sandall, J., Soltani, H., Gates, S., Shennan, A., \& Devane, D. (2013). Midwife-led continuity models versus other models of care for childbearing women. Cochrane Database of Systematic Reviews 2013, (8), CD004667. http:// dx.doi/10.1002/14651858.CD004667.pub3

Sandelowski, M. (2000). Whatever happened to qualitative description? Research in Nursing \& Health, 23, 334-340.

Sarasua, I., Clausen, C., \& Frunchak, V. (2009). Mothers' experiences with breastfeeding management and support: A quality improvement study. Breastfeeding Review, 17(1), 19-27.

Schatzman, L. (1991). Dimensional analysis: Notes on an alternative approach to the rounding of theory in qualitative research. In D. Maines (Ed.), Social organisation and social process: Essays in honour of Anselm Strauss (pp. 303-314). New York, NY: Aldine.

Schmied, V., Beake, S., Sheehan, A., McCourt, C., \& Dykes, F. (2011). Women's perceptions and experiences of breastfeeding support: A metasynthesis. Birth, 38(1), 49-60. http://dx.doi.org/10.1111/j.1523-536X.2010 $.00446 . \mathrm{x}$

Sheehan, A., Schmied, V., \& Barclay, L. (2009). Women's experiences of infant feeding support in the first 6 weeks post-birth. Maternal \& Child Nutrition, 5(2), $138-150$.

Tender, J., Janakiram, J., Arce, E., Mason, R., Jordan, T., Marsh, J., . . . Moon, R. Y. (2009). Reasons for in-hospital formula supplementation of breastfed infants from lowincome families. Journal of Human Lactation, 25(1), 11-17. http://dx.doi.org/10.1177/0890334408325821

Waldenstrom, U. (2004). Why do some women change their opinion about childbirth over time? Birth, 31(2), 102-107. http://dx.doi.org/10.111/j.0730-7659.2004 $.00287 . \mathrm{x}$

Williams, K., Lago, L., Lainchbury, A., \& Eagar, K. (2010). Mothers' views of caseload midwifery and the 
value of continuity of care at an Australian regional hospital. Midwifery, 26(6), 615-621. http://dx.doi .org/10.1016/j.midw.2009.02.003

Wilson, G. (2009). Implementation of releasing time to care-the productive ward. Journal of Nursing Management, 17(5), 647-654. http://dx.doi.org/10.1111/j .1365-2834.2009.01026.x

World Health Organization. (2002). The optimal duration of exclusive breastfeeding: A systematic review. Geneva, Switzerland: Author.

World Health Organization. (2007). Evidence on the long-term effects of breastfeeding: Systematic reviews and metaanalyses. Geneva, Switzerland: Author.

World Health Organization. (2009). Acceptable medical reasons for use of breast-milk substitutes. Geneva, Switzerland: Author.
Correspondence regarding this article should be directed to Danielle Gleeson, B. App. Sc. (Nursing), Grad. Dip. Mid. MMid (Research), Grad. Cert. Higher Ed., IBCLC, School of Nursing and Midwifery, Griffith University, University Drive, Meadowbrook, QLD, 4131, Australia. E-mail: danielle.gleeson@griffith.edu.auAv

Danielle B. Gleeson, B. App. Sc. (Nursing), Grad. Dip. Mid. MMid (Research), Grad. Cert. Higher Ed., IBCLC, School of Nursing and Midwifery, Griffith University, Australia Karen Flowers, RN, PhD, Faculty of Health Sciences, Australian Catholic University

Jennifer Fenwick, RM, BHSc(Nsg), MNgSt (Women's Health), PhD, School of Nursing and Midwifery, Griffith University, Australia. 